\title{
HLA-DR, DRw52.53, AND DQ HOMOZYGOSITY IN PATIENTS WITH NEURAL TUBE DEFECTS
}

\author{
Andrew C.W. Wong, ${ }^{1}$ Koji AokI, ${ }^{2}$ Yoshiaki YaGamI, ${ }^{2}$ \\ Tatsuya AKaza, ${ }^{3}$ Shoji Takeuchi, ${ }^{1}$ and \\ Takanobu MatSUNAGA ${ }^{1}$ \\ ${ }^{1}$ Department of Orthopaedic Surgery, Gifu University, School of Medicine, \\ Gifu 500, Japan \\ ${ }^{2}$ Department of Obstetrics and Gynaecology, Faculty of Medicine, \\ Nagoya City University, Nagoya 467, Japan \\ ${ }^{3}$ Tissue Typing Laboratory, Nagoya II Red Cross Hospital, \\ Nagoya 466, Japan
}

\begin{abstract}
Summary Studies of the possible relationship between malformations of the neuraxis and the human major histocompatibility complex have been contributive to the search for a human equivalent of the murine $T / t \mathrm{com}$ plex. We conducted a population and family study in 34 Japanese couples together with their children with neural tube defects. HLA-DR homozygosity among the affected children was significantly increased as compared with that in controls. HLA-DR and DQ maternal-paternal sharing was also significantly higher than the controls. Significantly higher frequencies of A11 (father), B35 (mother) and A11 (affected children) were observed. These data support the hypothesis that a $\mathrm{T} / \mathrm{t}$-like complex in or near the HLA complex might be etiologically related to neural tube defects.
\end{abstract}

\section{INTRODUCTION}

While the aetiology of neural tube defects (N.T.D.) remains inadequately understood, their occurrence may reasonably be explained by the interaction of environmental factors with genetic predisposition (Carter, 1970; Carter and Evans, 1973; Fraser, 1976). As to the genetic predisposition, much attention has been paid to a restricted region on mouse chromosome 17 , which contains an important gene complex controlling stages in early embryogenesis. It has been known for nearly fifty years that mutations in the so called $\mathrm{T} / \mathrm{t}$ complex in mice resulted in different kinds of congenital malformations (Bennett, 1975; Pious, 1975). Close chromosomal proximity of the $\mathrm{T} / \mathrm{t}$ complex and the $\mathrm{H}-2$ complex (15 crossover units) means that

Received April 17, 1985; final revised version received June 1, 1986; Accepted July 20, 1986 
mutations in alleles of the $T$ system are associated with atypical patterns of inheritance of histocompatibility antigens (Bennett, 1975; Klein and Hammerburg, 1977; Macri et al., 1981).

$\mathrm{H}-2$ is associated with the reproductive performance by a genetic linkage with the $T / t$ complex. This complex consists of a series of semidominant alleles which is highly polymorphic and, if homozygous, leads to stage specific failures in early embryonic development and fetal death (Bennett, 1975). It has been suggested that some evolutionary biological relationships between the $\mathrm{T} / \mathrm{t}$ and $\mathrm{H}-2$ complexes are present: Certain characteristics of the $\mathrm{T} / \mathrm{t}$ complex may be due to segregation distortion of certain allels (the mutant $t$ being favored) and $T / t$ complex-induced suppression of recombination may extend into the H-2 region (Klein and Hammerburg, 1977). Considering the analogies between $\mathrm{H}-2$ and HLA, the presence of a human analogue of the $\mathrm{T} / \mathrm{t}$ complex linked to HLA might be postulated based on the evolutionary conservation of many features of the major histocompatibility complex (Snell et al., 1976). Evidence for a reciprocal temporal relationship between F9 (a public antigen of $\mathrm{T} / \mathrm{t}$ complex) and $\mathrm{H}-2$ expression in early mouse embryos (Jacob, 1977) and F9 and HLA in human teratomas strengthens this argument (Buc-Caron et al., 1974; Hogan et al., 1977; Holden et al., 1977).

To examine the hypothesis that a putative $\mathrm{T} / \mathrm{t}$ complex-like region in or near the HLA complex is related to neural tube defects in man, the sample of 34 families with children of spina bifida or anencephaly were studied.

\section{MATERIALS AND METHODS}

In the present study 34 N.T.D. affected families from Central Japan were examined. They were 23 couples with children of spina bifida with myelomeningocele and 11 couples with stillborns of anencephaly. The children examined were 18 patients with myelomeningocele and five patients with anencephaly. No consanguinity was observed. Unaffected sibs of these patients were not available for tissue typing. All mothers were in their twenties when they gave birth to the patients during 1978-1984. Obstetrical and gynaecological abnormalities were not observed among the mothers, and chromosomal and sperm analysis were normal on the father's side.

The control consisted of the following; 206 unrelated healthy individuals were typed on HLA-A and -B antigens, from which 180 were also typed on HLA-DR, DRw52.53, and DQ antigens. The control families for the comparison of children homozygosity and maternal-paternal sharing at HLA-A, -B, -DR, -DRw52.53, and DQ loci were 90 unrelated healthy families (one family included both parents and two children). The criteria for selection of these 90 control families were that they were unrelated and each family had at least two healthy children delivered normally and without a history of involuntary fetal wastage or offspring with neural tube defects. All control members were from Gifu and Aichi prefectures, Central Japan. 
Heparinized blood, taken by venopuncture, provided a mononuclear cell suspension prepared by Ficoll-Hypaque density centrifugation. T and B lymphocytes were isolated according to the thrombin-nylon wool column method (Danilovs et al., 1978). The purities of $\mathrm{T}$ and $\mathrm{B}$ lymphocytes were checked by sheep erythrocyte rosetting method and reactions with rabbit anti-B antisera. Only B specimens of purity more than $80 \%$ were utilized for HLA-DR, DRw52.53, and DQ typing.

All T lymphocytes were tested for eight HLA-A and 19 HLA-B specificities using about two monospecific antisera defining each of the following HLA antigens: $\mathrm{A} 1, \mathrm{~A} 2, \mathrm{~A} 3, \mathrm{~A} 9, \mathrm{~A} 11, \mathrm{~A} 26, \mathrm{~A} 31$, and Aw33; and B7, B8, B12, B13, B14, B15, B17, $\mathrm{B} 27, \mathrm{~B} 35, \mathrm{~B} 37, \mathrm{~B} 39, \mathrm{~B} 40, \mathrm{Bw} 46, \mathrm{Bw} 48, \mathrm{~B} 51, \mathrm{~B} w 52, \mathrm{Bw} 54, \mathrm{Bw55}, \mathrm{Bw59}$, Bw4, and Bw6. HLA-DR, DRw52.53, and DQ typing was performed with B lymphocytes using a panel of 60 platelet-absorbed antisera for the following ten HLA-DR and three HLA-DQ specificities: DR1, DR2, DR3, DR4, DR5, DRw6, DRw7, DRw8, DRw9, and DRw10; and DQw1, DQw2, and DQw3. DP antigens were not included in this study. Tissue-typing was done by the National Institute of Health standard lymphocyte microcytotoxicity test (Terasaki et al., 1978). All antisera were produced and supplied by Tissue Typing Laboratory, Nagoya II Red Cross Hospital, Central Japan.

Statistical significance of differences in gene frequency was subjected to a $2 \times 2$ chi-square test with Yates' correction for association. $\mathrm{P}$ values were corrected for the number of HLA specificities tested to account for the chance significance. Expression of HLA-A, B, DR, DRw52.53 and DQ antigens of the parents and children of the 34 affected families were compared to those of the 206 healthy individuals. HLA-A, B, DR and DQ maternal-paternal sharing were compared between the 90 control couples and parents of the patients. HLA-A, B, DR, DRw52.53 and DQ homozygosity were compared between the patients and the children of the control familes.

\section{RESULTS}

Haplotype segregation in 23 out of 34 N.T.D. affected families are shown in Table 1 and Table 2. Parental phenotypes of the remaining 11 families are shown in Table 3. There was a higher gene frequency of HLA-A11 among the father of the patients than the control of 206 unrelated healthy individuals $\left(\chi^{2}=16.62, \mathrm{p}_{\mathrm{a}}<\right.$ 0.008 , relative risk $=4.50$ ). This was also true for the expression of HLA-B 35 among the mother of the patients $\left(\chi^{2}=7.55, \mathrm{p}<0.01\right.$, relative risk $\left.=3.04\right)$. The patients showed a higher gene frequency of HLA-A $11\left(\chi^{2}=4.62, \mathrm{p}<0.05\right.$, relative risk $=$ 2.70). No significant deviations were found with the antigens on the $B$ locus. There was neither significant difference in the expression of HLA-DR nor -DQ antigens.

Frequencies of antigen sharing at HLA-A and HLA-B loci in N.T.D. families were higher but not significant as compared to those of the 90 control couples. Seventeen couples $(50 \%)$ shared at least one antigen at A-locus in the 34 N.T.D. 
Table 1. HLA haplotype segregation in N.T.D, families affected with DR homozygous children.

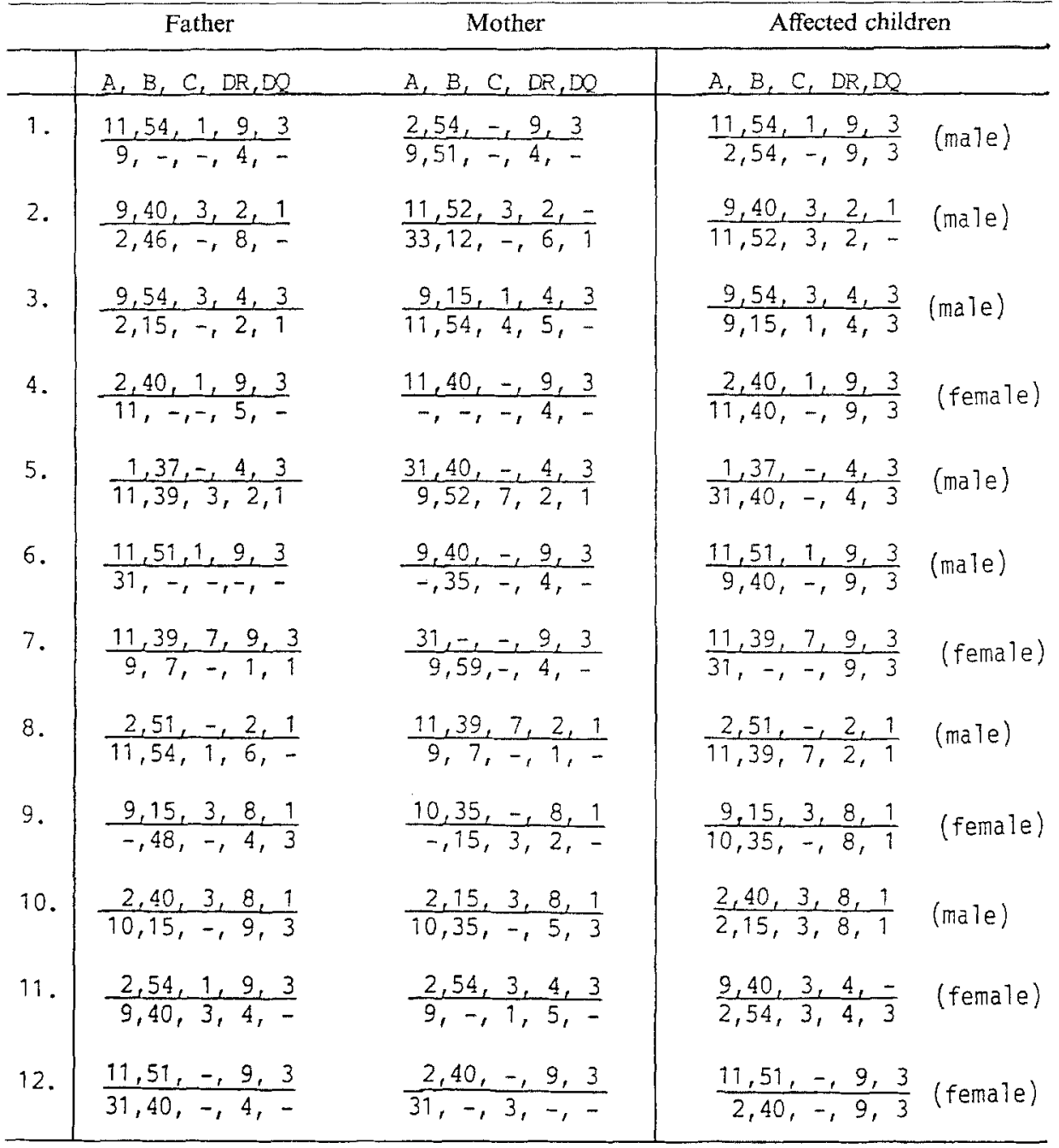

affected families, while the 41 couples $(45.6 \%)$ did in the 90 controls. At B-locus, sharing of one or two antigens occurred in 11 couples $(32.4 \%)$ as compared to 17 control couples $(18.9 \%$ ). As are shown in Fig. 1, sharing of one or two antigens on DR-locus was significantly increased: DR sharing was $61.8 \%$ among the N.T.D. parents and $30 \%$ among the control couples. Twenty-one out of 34 couples with affected children shared at least one antigen $\left(\chi^{2}=10.49, \mathrm{p}<0.001\right)$. DQ sharing was also increased $\left(\chi^{2}=5.47, \mathrm{p}<0.025\right)$. DRw52.53 sharing was not significant (Fig. 1).

As are shown in Table 4, there was a significant increase in HLA-DR homozygosity among the patients when compared to the 180 normal children of the 90 
Table 2. HLA haplotype segregation in N.T.D. families affected with DR heterozygous children.

\begin{tabular}{|c|c|c|c|}
\hline & Father & Mother & Affected children \\
\hline & $A, B, C, D R, D Q$ & $A, B, C, D R, D Q$ & $A ; B, C, D R, D Q$ \\
\hline 1. & $\frac{9,7,7, \frac{1,1}{31,54,1,}}{4,3}$ & $\frac{9,52,-,-2,-\frac{1}{3}}{2,40,-,}$ & 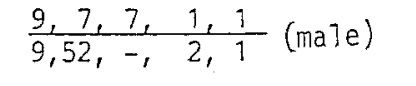 \\
\hline 2. & $\frac{9,7,7,-1,1}{-, 40,-1,9,3}$ & $\frac{2,39,7, \quad 8,1}{-, 35,-, \quad-,}$ & 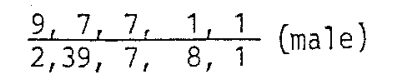 \\
\hline 3. & $\frac{33,12,1,6,1}{31,-,-3,-1,-}$ & 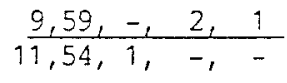 & 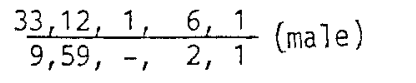 \\
\hline 4. & $\frac{9,54,1,8,3}{-, 35,-,-5,-}$ & $\frac{9,40,-,}{-, 52,-,} \frac{9,}{2,} 3$ & 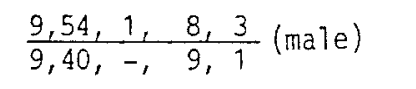 \\
\hline 5. & $\frac{33,12,-, 6,1}{10,40,3,2,-}$ & $\frac{2,59,-, 4,3}{9,7,-, 1,}$ & $\frac{33,12,-, 6,1}{2,59,-, 4,3}$ (male) \\
\hline 6. & $\frac{9,52,3,2,1}{2,40,-,}$ & $\frac{10,35,-, 4,3}{33,12,3,6,1}$ & $\frac{9,52,3,2,-\frac{1}{3}}{10,35,-,}$ (fema 7 e) \\
\hline 7. & $\frac{11,15,4,4,3}{9,37,-1,-1,}$ & $\frac{2,35,3,}{10,40,-1,2,} \frac{1}{-}$ & $\frac{11,15,4,-4,3}{2,35,3,8,1}$ (male) \\
\hline 8. & $\frac{9,54,1,4,3}{2,35,-,}$ & 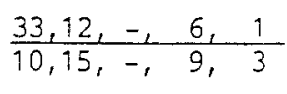 & $\frac{9,54,1,4,3}{33,12,-6,1}$ \\
\hline 9. & $\frac{2,51,3,6,6,1}{11,35,-2,5,3}$ & $\frac{2,35,4,-4,}{11,54,1,-\frac{3}{1}}$ & $\frac{2,51,3,6, \frac{1}{4,3}}{2,35,4,4,3}$ (fema 1e) \\
\hline 10. & $\frac{-, 13,-,-7,2}{9,40,3,6,1}$ & $\frac{1,37,6,10,1}{10,13,3,6,}$ & $\frac{-, 13,-, 7,2}{1,37,6,10,1}$ (fema le) \\
\hline 11. & 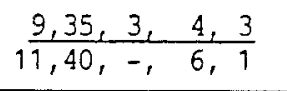 & $\frac{33,17,3,}{2,46,}, \frac{-}{1,}-$ & $\frac{9,35,3,}{33,17,3,} \frac{4,3}{3,1}$ \\
\hline
\end{tabular}

control families $\left(\chi^{2}=25.57, \mathrm{p}<0.0001\right)$. Twelve out of 23 typed patients were DR homozygotes whereas only 20 in 180 normal children were homozygous for DR. HLA-DQ homozygosity was also increased but the difference was not significant. Among the 11 deceased patients, parental DR sharing occurred in seven families $(63.3 \%)$ and DQ sharing in all families $(100 \%)$ (Table 3 ).

\section{DISCUSSION}

The HLA disease associations have been summarized by Dausset (1977), Dausset and Svejgaard (1977), Pietrzyk and Turowski (1976), and Naito (1986). An association, whether strong or weak, implies a genetic contribution to etiology of the particular disease. Earlier investigators studying the genetics of N.T.D. suggested 
Tatile 3. Maternal-paternal DR, DQ sharing in N.T.D. families with affected deceased ch ildren (not-typed) $\mathrm{N}=11 / 34$

\begin{tabular}{|c|c|c|c|c|c|c|c|c|c|c|c|}
\hline & \multicolumn{5}{|c|}{ Father } & \multicolumn{5}{|c|}{ Mother } & \multirow{2}{*}{ Affected children } \\
\hline & A. & B & $\mathrm{C}$ & DR & DQ & A & B & $\mathrm{C}$ & DR & DQ & \\
\hline 1. & 2,9 & $52,-$ & $1,-$ & $* 2,6$ & $1,-$ & 11,33 & $12,-$ & $-\rightarrow-$ & $* 6,-$ & $1,-$ & a (male) \\
\hline 2. & 2,11 & $40,-$ & $7,-$ & $* 2,5$ & 1,3 & $9,-$ & $35,-$ & $3,-$ & $* 2,4$ & 1,3 & Spina bifida (male) \\
\hline 3. & 2,9 & 52,48 &,-- & $* 2,-$ & $1,-$ & 2,9 & 51,54 & $1,-$ & $*_{2,4}$ & 1,3 & Spina bifida (male) \\
\hline 4. & 2,9 & 51,35 & $3,-$ & $* 8,9$ & 1,3 & 9,11 & $40,-$ &,-- & $* 8,9$ & 1,3 & Anencephaly (female) \\
\hline 5. & 10,11 & 39,40 & 3,7 & $*_{5}, 8$ & 1,3 & $9,-$ & 51,46 & $1,-$ & $* 8,9$ & 1,3 & Anencephaly (male) \\
\hline 6. & 2,11 & 35,54 & $3,-$ & $* 4,9$ & $3,-$ & 31,33 & 54,12 & $3,-$ & $* 4,8$ & 1,3 & Anencephaly (female) \\
\hline 7. & 9,10 & 7,39 & $7,-$ & $* 1,2$ & $1,-$ & 2,9 & 52,40 & $3,-$ & $* 2,5$ & 1,3 & Anencephaly (female) \\
\hline 8. & $2,-$ & 70, & 1,3 & T, & $J_{0}$ & 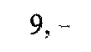 & 51,35 & $3,-$ & 2,5 & 1,3 & Anencephaly (male) \\
\hline 9. & 2,11 & 59,55 & $1,-$ & $4,-$ & $3,-$ & 9,33 & 35,7 & $3,-$ & 1,5 & 1,3 & Anencephaly (female) \\
\hline 10. & 2,11 & 55,40 & $1,-$ & 4,9 & $3,-$ & $9,-$ & 51,55 & $1,-$ & 2,5 & 1,3 & Spina bifida (male) \\
\hline 11. & 2,11 & 15,54 & 1,4 & $4,-$ & $3,-$ & $2,-$ & 35,40 & $3,-$ & 2,9 & 1,3 & Spina bifida (female) \\
\hline
\end{tabular}

* DR sharing in 7 out of 11 families.

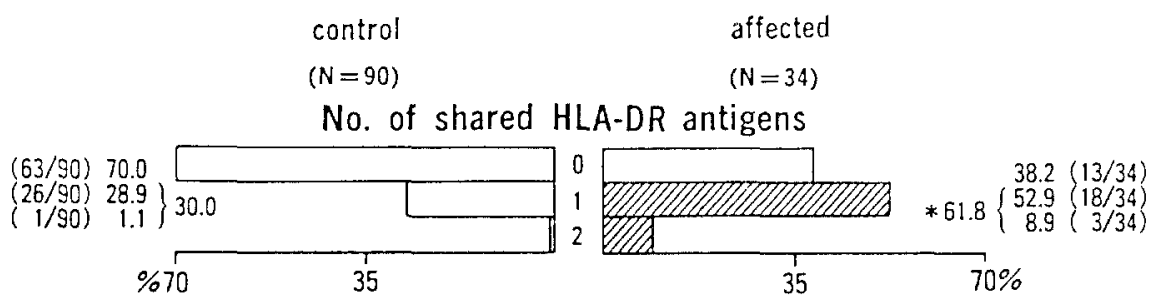

No. of shared HLA-DRw52.53 antigens

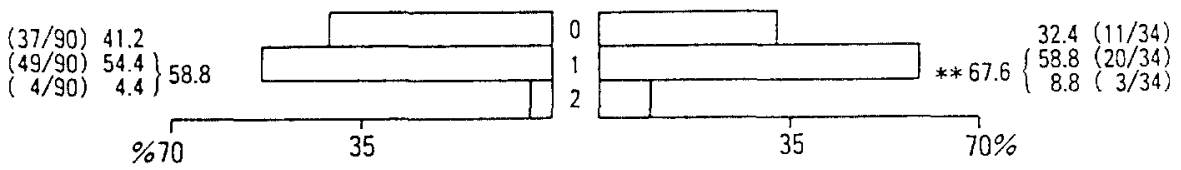

No. of shared HLA-DQ antigens

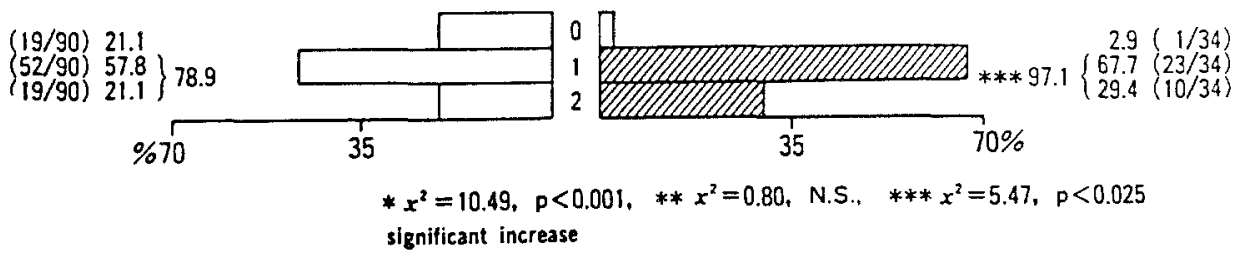

Fig. 1. Frequencies of shared HLA-DR, DRw52.53, and DQ antigens in parents of N.T.D. and the control couples. 
Table 4. HLA-DR, DRw52.53 and DQ homozygosity in N.T.D. affected children.

\begin{tabular}{|c|c|c|c|c|c|c|c|c|}
\hline \multirow[b]{2}{*}{ Spina bifida } & \multirow{2}{*}{$\frac{\mathrm{N}}{: 18}$} & \multicolumn{2}{|c|}{$\begin{array}{c}\text { DR } \\
\text { homozygote }\end{array}$} & \multicolumn{2}{|c|}{$\begin{array}{c}\text { DRw52.53 } \\
\text { homozygote }\end{array}$} & \multicolumn{2}{|c|}{$\begin{array}{c}\text { DQ } \\
\text { homozygote }\end{array}$} & \multirow{2}{*}{$\begin{array}{l}\text { Statistical significance } \\
\text { DR homozygosity } \\
y^{2}=19.80, p<0.001\end{array}$} \\
\hline & & 9 & $(50.0 \%)$ & 12 & $(66.7 \%)$ & 11 & $(61.1 \%)$ & \\
\hline Anencephaly & $y: 5$ & 3 & $(60.0 \%)$ & 4 & $(80.0 \%)$ & 3 & $(60.0 \%)$ & $\begin{array}{l}\text { DR homozygosity } \\
x^{2}=6.68, \quad p<0.025\end{array}$ \\
\hline $\begin{array}{l}\text { N.T.D. } \\
\text { (S.B. \& AN }\end{array}$ & $\begin{array}{c}: 23 \\
\text { JEN.) }\end{array}$ & 12 & $(52.2 \%)$ & 16 & $(69.6 \%)$ & 14 & $(60.9 \%)$ & $\begin{array}{l}\text { DR homozygosity } \\
y^{2}=25.57, p<0.0001\end{array}$ \\
\hline Control* $^{*}$ & $: 180$ & 20 & $(11.1 \%)$ & 114 & $(63.3 \%)$ & 85 & $(47.2 \%)$ & \\
\hline
\end{tabular}

* Control : 180 children from 90 normal and unrelated familes ( 2 children from each family).

that a recessive gene was probably responsible for the occurrence of most N.T.D. (Book and Rayner, 1950; Penrose, 1957, 1946; Polman, 1951). Later, multifactorial determination of N.T.D. was postulated based on the fact that environmental and complex genetic factors appear to affect frequency and distribution of these abnormalities (Carter et al., 1968; Carter, 1968, 1976; Richards et al., 1972; Williamson, 1965; Yen and MacMahon, 1968). Linkage between spina bifida and the HLA complex was shown by Amos et al. (1975) and Mendell (1974). No evidence of association, however, was found by Bobrow et al. (1978) and Vannier et al. (1980).

Some similarities are observed between our data and those of Schacter's report (Schacter et al., 1979) in that HLA-A1l was significantly increased among the fathers, HLA-B35 among the mothers and HLA-A11 among the patients. HLA-A, -B maternal-paternal sharing was increased in Schacter's study though the difference was not significant in this study. Increase in parental HLA-DR and DQ sharing was significant in our series. HLA-DR homozygosity among the patients was significantly increased: Of 23 patients typed, 12 carried homozygous alleles at DR-locus $(52.8 \%)$, as compared to only 20 homozygotes of 180 normal children $(11.6 \%)$. Among the parents of the 11 patients who deceased and were not typed, there is a high degree of HLA-DR and DQ sharing: Seven out of 11 couples shared at DRlocus $(63.6 \%)$ and all couples shared at DQ-locus (100\%). Feingold et al. (1980) reported an association between spina bifida and anencephaly with HLA-A1, B5, B8 and B35, and suggested a possible genetic background of susceptibility to these malformations. HLA-B35 was found to show a higher gene frequency in the present study among the mothers of the patients.

Although there are similarities between the results in the present study and those of earlier reports, conclusion concerning an association between N.T.D. and HLA is still premature. The present study has been performed on the Japanese population with a lower rate of N.T.D. occurrence as summarized by Imaizumi (1977) compared with Caucasians. Our study did not test directly the hypothesis of a 
human $\mathrm{T} / \mathrm{t}$-like complex linked to HLA. However, our data might warrant further investigation on the association of the HLA system with birth defects in man. Our present study also failed to include HLA typing of unaffected sibs of N.T.D. patients in families. Further analysis of HLA haplotype segregation in these healthy sibs would certainly be complementary for the present study on the HLA system and N.T.D. A more extensive study on comparison of segregation and linkage analyses in large N.T.D. pedigrees among different ethnic groups is underway.

Acknowledgments The authors wish to express deep thanks to the patients and their families for their cordial cooperation and understanding in helping us to conduct this survey.

\section{REFERENCES}

Amos, D.B., Ruderman, N., Mendell, N., and Johnson, A.H. 1975. Linkage between HLA and spinal development. Transpl. Proc. 7: 93-95.

Bennett, D. 1975. The T-locus of the mouse. Cell 6: 441-454.

Bobrow, M., Bodmer, J.G., Bodmer, W.F., McDevitt, H.O., Lorber, J., and Swiit, P. 1978. The search for a human equilvalent of the mouse T-locus-negative results from a study of HLAtypes in spina bifida. Tissue Antigens 5 : 234-237.

Book, J.A. and Rayner, S. 1950. A clinical and genetic study of anencephaly. Am. J. Hum. Genet. 2: 61-84.

Buc-Caron, M., Gachelin, G., Hofnung, M., and Jacob, F. 1974. Presence of a mouse embryonic antigen on human spermatozoa. Proc. Natl. Acad. Sci. USA 71: 1730-1733.

Carter, C.O., David, P.A., and Laurence, K.M. 1968. A family study of major central nervous system malformations in South Wales. J. Med. Genet. 5: 81-106.

Carter, C.O. 1968. Genetics of common disorders. Br. Med. Bull. 25: 52-57.

Carter, C.O. 1970. Congenital Malformations. Excerpta Medica, Amsterdam.

Carter, C.O. and Evans, K. 1973. Spina bifida and anencephaly in Greater London. J. Med. Genet. 10: 209-234.

Carter, C.O. 1976. Genetics of common single malformations. Br. Med. Bull. 32: 21-26.

Danilovs, J., Terasaki, P.I., Park, M.S., and Ayoub, G. 1978. B-lymphocyte isolation by thrombin nylon wool. 8th International Histocompatibility Workshop, Newsletter, 6.

Dausset, J. 1977. HLA complex in human biology in the light of associations with disease. Transplant. Proc. 9: 523-529.

Dausset, J. and Svejgaard, A. 1977. HLA and Disease. Munksgaard, Copenhagen.

Feingold, J., Feingold, N., and Bois, E. 1980. Geographic correlation with the HLA system. Tissue Antigens 15: 318-324.

Fraser, F.C. 1976. The multifactorial threshold concept-uses and misues. Teratology 14: 267280.

Hogan, B., Fellous, M., Arner, P., and Jacob, F. 1977. Isolation of a human teratoma cell line which expresses $\mathrm{F} 9$ antigen. Nature 270 : 515-518.

Holden, S., Bernard, O., Artzt, K., Whitmore, A., and Bennett, D. 1977. Human and mouse embryonal carcinoma cells in culture share an embryoinc antigen (F9). Nature 270: 518-520.

Imaizumi, Y. 1977. Incidence of spina bifida and parental consanguinity in Japan. Cong. Anoma. 17: $471-478$.

Jacob, F. 1977. Mouse teratocarcinoma and embryonic antigens. Immunol. Rev. 33: 3-32.

Klein, J. and Hammerburg, C. 1977. The control of differentiation by the T-complex. Immunol. Rev. 33: 70-104. 
Macri, J.N., Baker, D.A., and Baim, R.S. 1981. Diagnosis of neural tube defects by evaluation of amniotic fluid. Clin. Obstet. Gynaec. 24: 1089-1102.

Mendell, N.R. 1974. Spina bifida and the HLA system: evidence for linkage. Am. J. Hum. Genet. 26: 60 ,

Naito, S. 1986. The association of HLA with diseases in Japanese. Jph. J. Human Genet. 31: 323-329.

Penrose, L.S. 1957. Genetics of anencephaly. J. Ment. Defic. Res. 1: 4-15.

Penrose, L.S. 1946. Familial data on 144 cases of anencephaly, spina bifida and congenital hydrocephaly. Ann. Eugenics 13: 73-98.

Pietrzyk, J.J. and Turowski, G. 1976. Antygeny HLA; genetyczne determinanty choroby. Pol. Arch. Med. Wewn. 55: 487-498.

Pious, D. 1975. Cell surfaces genetics and congenital malformations. J. Pediatr. 86: 162-188.

Polman, A. 1951. Anencephaly, spina bifida and hydrocephaly. Genetica 25: 29-31.

Richards, I.D., McIntosh, H.T., and Sweenie, S. 1972. A genetic study of anencephaly and spina bifida in Glasgow. Dev. Med. Child. Nerol. 14: 626-639.

Schacter, B., Muir, A., Gyves, M., and Tasin, M. 1979. HLA-A, B compatibility in parents of offspring with neural tube defects or couples experiencing involuntary fetal wastage. Lancet I: 796-799.

Snell, G.D., Dausset, J., and Nathenson, S. 1976. Histocompatibility genes and disease. In Histocompatibility. Sneli, G.D., Dausset, J., and Nathenson, S., eds., Academic Press, New York, pp. 324-389.

Terasaki, P.I., Bernoco, D., Park, M.S., Ozturk, G., and Iwaki, Y. 1978. Microdroplet testing for HLA-A, B, C, and D antigenes. Am. J. Clin. Pathol. 69: 103-120.

Vannier, J.P., Cavelier, B., Martin, J.P., Lefort, J., Rivat, L., and Feingold, 1980. HLA, Pi, Gm, $\mathrm{Km}$ phenotypes in a spina bifida population with myelomeningocele. Tissue Antigens 15 : 501-504.

Williamson, E.M. 1965. Incidence and family aggregation of major congenital malformation of central nervous system. J. Med. Genet. II: 161-172.

Yen, S. and MacMahon, B. 1968 . Genetics of anencephaly and spina bifida. Lancet II: $623-626$. 